\title{
Gastroparesis Symptoms Associated with Intestinal Hypomotility: An Explorative Study Using Wireless Motility Capsule
}

\author{
Mattis Bekkelund (D) 1,2 \\ Dag A Sangnes (iD) ${ }^{2-4}$ \\ Eirik Søfteland (iD ${ }^{3-5}$ \\ Lars Aabakken 1,6 \\ Martin Biermann (iD) ${ }^{4,7}$ \\ Elisabeth K Steinsvik ${ }^{2,4,8}$ \\ Trygve Hausken ${ }^{2,8}$ \\ Georg Dimcevski ${ }^{4,8}$ \\ Jan Gunnar Hatlebakk (D) ${ }^{2-4}$ \\ 'Department of Clinical Medicine, \\ University of Oslo, Oslo, Norway; \\ ${ }^{2}$ Norwegian Competence Centre for \\ Functional Gastrointestinal Disorders, \\ Department of Medicine, Haukeland \\ University Hospital, Bergen, Norway; \\ ${ }^{3}$ Department of Medicine, Haukeland \\ University Hospital, Bergen, Norway; \\ ${ }^{4}$ Department of Clinical Medicine, \\ University of Bergen, Bergen, Norway; \\ ${ }^{5}$ Hormone Laboratory, Haukeland \\ University Hospital, Bergen, Norway; \\ ${ }^{6}$ Department of Transplantation \\ Medicine, Section for Gastroenterology, \\ Oslo University Hospital, Oslo, Norway; \\ ${ }^{7}$ Centre for Nuclear Medicine and PET, \\ Department of Radiology, Haukeland \\ University Hospital, Bergen, Norway; \\ ${ }^{8}$ National Centre for Ultrasound in \\ Gastroenterology, Haukeland University \\ Hospital, Bergen, Norway
}

Correspondence: Mattis Bekkelund Norwegian Competence Centre for Functional Gastrointestinal Disorders, Department of Medicine, Haukeland University Hospital, Bergen, 502I, Norway

Tel +4748186897

Email mattis.bekkelund@hotmail.com
Objective: Gastric emptying measurements are mandatory in gastroparesis diagnostics, but the association between delayed emptying and symptoms is questionable. It is imperative to find biomarkers better correlated to symptom generation. Hence, we examined the association between symptom severity and gastrointestinal motility measured by wireless motility capsule.

Patients and Methods: In this prospective single-centre study, patients with gastroparesis symptoms were simultaneously investigated with gastric emptying scintigraphy and wireless motility capsule, measuring regional transit times and contractility parameters. Symptom severity was assessed with the Patient Assessment of Upper Gastrointestinal Symptom Severity Index (PAGI-SYM), including the Gastroparesis Cardinal Symptom Index (GCSI). Results: We included 107 patients (70\% women). In the whole patient group, nausea correlated with the gastric $\left(r_{s}=-0.31, p=0.007\right)$, small bowel $\left(r_{s}=-0.41, p<0.001\right)$ and colonic $\left(r_{s}=-0.33, p=0.012\right)$ motility indices. In patients with idiopathic etiology, nausea correlated with small bowel motility index $\left(r_{s}=-0.81, p<0.001\right)$ and mean stomach pressure $\left(r_{s}=-0.64, p=0.013\right)$. We also found negative correlations between total GCSI score and maximum pressure of the small bowel $\left(r_{s}=-0.77, p<0.001\right)$ and colon $\left(r_{s}=\right.$ $-0.74, p=0.002)$. In diabetes patients, total PAGI-SYM score correlated with colonic motility index $\left(r_{s}=-0.34, p=0.012\right)$, and mean pressure of the colon correlated with upper abdominal pain $\left(r_{s}=-0.37, p=0.007\right)$. We found no association between symptoms, gastric emptying nor any other transit times.

Conclusion: In patients with gastroparesis symptoms, we found that symptom severity was associated with intestinal hypomotility. Based on these results, gastroparesis diagnostics should also include an evaluation of the small bowel and colon.

Keywords: gastric emptying, gastrointestinal motility, gastroparesis, gastroparesis-like syndrome, small bowel, wireless motility capsule, scintigraphy

\section{Introduction}

Gastroparesis is defined by delayed gastric emptying in the absence of mechanical obstruction. ${ }^{1}$ Cardinal symptoms are nausea and vomiting, bloating and postprandial fullness, but abdominal pain and fatigue are also common. ${ }^{2}$ Gastroparesis-like syndrome is a diagnostic group where patients have symptoms of gastroparesis, similar histopathological alterations, similar response to therapy, but normal gastric emptying. ${ }^{3-5}$ Furthermore, the distinction between gastroparesis, gastroparesis-like syndrome and functional dyspepsia is unclear. Most gastroparesis patients fulfill the 
Rome criteria for functional dyspepsia, while more than $25 \%$ of the patients with functional dyspepsia have delayed gastric emptying, blurring the distinction further. $^{6-8}$

Several underlying conditions may lead to gastroparesis, including diabetes mellitus, iatrogenic causes such as medications or surgery, neurological disorders such as Parkinson's disease and rheumatic disorders., ${ }^{9,10}$ In a subset of patients, no underlying cause is found. However, the pathophysiology is gradually becoming unraveled, and in a subgroup of the patients, a prior infection may be the underlying cause. ${ }^{11}$

Gastric emptying scintigraphy is the current gold standard for gastric emptying measurements, but the association between delayed emptying and symptoms is

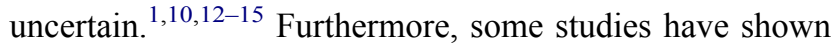
dysmotility of the small bowel or colon in a subgroup of patients with gastroparesis, indicating the need for more extensive gastrointestinal motility assessment. ${ }^{16-20}$ However, the gold standard for measuring small bowel and colonic motility, catheter-based manometry, is invasive and unpleasant for the patients and show little relation to symptoms. Interpretation also requires specialized qualifications, and the method therefore has limited availability. ${ }^{21}$ In recent years, the wireless motility capsule (SmartPill $^{\circledR}$, Medtronic Inc., Minneapolis, USA) has emerged as a potential diagnostic alternative. The wireless motility capsule is a non-digestible capsule measuring pressure, $\mathrm{pH}$, and temperature throughout the gastrointestinal tract. In addition to gastric emptying time, the capsule assesses motility in other gastrointestinal regions. However, the literature relating wireless motility capsule findings and symptoms is still limited.

Consequently, the aim of this study was to explore the association between symptom severity, transit times and contractility parameters measured by the wireless motility capsule in a cohort of patients with gastroparesis symptoms.

\section{Patients and Methods}

Patients with symptoms compatible with gastroparesis referred to Haukeland University Hospital, Bergen, Norway, from their local hospital, were prospectively included from 2014 to 2018. Symptoms of gastroparesis and previous upper endoscopy to exclude mechanical obstruction were inclusion criteria in this study.

Medications potentially affecting gastrointestinal motility were paused before and during the study, including proton pump inhibitors ( 7 days in advance), histamine $\mathrm{H}_{2}$ receptor antagonists, opioid analgesics, nonsteroidal antiinflammatory drugs, anti-diarrheal drugs, prokinetic agents, antiemetic drugs (3 days in advance), laxatives (two days), and over-the-counter antacids and alginates (24 hours). Ingestion of alcoholic drinks was not allowed for the last 48 hours and during examinations. Inability to cooperate during medical procedures, pregnancy, breast feeding or failure to discontinue medications excluded the patient from the study.

\section{Motility Tests}

Following an overnight fast from 8 PM, patients underwent simultaneous assessment by wireless motility capsule and gastric emptying scintigraphy starting at 9 AM. To allow for simultaneous testing, patients first ingested a cereal bar $\left(\right.$ SmartBar $^{\circledR}$, Medtronic Inc., Minneapolis, USA; containing $260 \mathrm{kcal}, 75 \%$ carbohydrate, $21 \%$ protein, 3\% fat, 3\% fiber) together with a boiled egg radiolabeled with Tc-99m-nanocolloid (75 kcal, 1.1\% carbohydrate, $13 \%$ protein, $11 \%$ fat, $0 \%$ fiber). Immediately afterwards, the wireless motility capsule was swallowed. Together with the meal, patients were allowed to drink $120 \mathrm{~mL}$ of still water. The patient then had to fast for another 6 hours but could drink an additional $100 \mathrm{~mL}$ of water.

\section{Gastric Emptying Scintigraphy}

Using a double-headed camera system (Siemens e.cam; Siemens Healthineers Inc., Hoffman Estates, USA), anterior and posterior images of the patient in the supine position were obtained 30 minutes, 1, 2, 3 and 4 hours after meal ingestion. Regions of interest were identified as previously described. ${ }^{15}$ Delayed gastric emptying was defined as greater than $10 \%$ residual activity after 4 hours as recommended by Abell et al. ${ }^{22}$

\section{Wireless Motility Capsule}

The wireless motility capsule is a $26.8 \times 11.7 \mathrm{~mm}$ capsule coated with polyurethane. It contains a radio transmitter, an antenna, two $1.5-\mathrm{V}$ batteries and sensors measuring $\mathrm{pH}$ (range $0.5-9.0)$, pressure $(0-350 \mathrm{mmHg})$ and temperature $\left(25-49^{\circ} \mathrm{C}\right) .^{23}$ After ingestion, data were continuously transmitted to a wireless recorder worn by the patient during the entire examination. After five days, patients returned the recorder, whereupon data was transferred to a personal computer and analyzed using the MotiliGI ${ }^{\circledR}$ software (Medtronic Inc.). Changes in $\mathrm{pH}$ were used to 
identify the gastric and small bowel regions. ${ }^{24,25}$ In patients where these landmarks were hard to define, consensus was obtained between two or more investigators.

Motility and contractility parameters calculated for each region included transit time, contractions per minute, mean pressure, maximum amplitude of contractions and the motility index. ${ }^{24}$ The motility index is a parameter integrating all contractions $>10 \mathrm{mmHg}$ over baseline pressure as an area under the pressure-time curve, as originally described by Ouyang et al. ${ }^{26}$ The motility index as it appears in MotiliGI is shown in Figure 1.

\section{Questionnaires}

To assess patients' symptoms, we used the Patient Assessment of Upper Gastrointestinal Symptom Severity Index (PAGI-SYM), a standardized questionnaire validated for this patient group. ${ }^{27}$ Patients received the questionnaire by mail and were instructed to complete it prior to arrival.

PAGI-SYM consists of 20 questions regarding upper gastrointestinal symptoms during the preceding 2 weeks. Each question is graded from 0 to 5 on a Likert scale. PAGI-SYM has six subscales: 1) nausea/vomiting, 2) fullness/early satiety, 3) bloating, 4) upper abdominal pain, 5) lower abdominal pain and 6) heartburn/regurgitation. ${ }^{28}$ In this study, we discarded questions regarding lower abdominal pain or discomfort and heartburn/regurgitation. The Gastroparesis Cardinal Symptom Index (GCSI) is calculated by averaging the scores of subscales $1-3 .{ }^{29}$ GCSI scores are graded into mild (0-2.99), moderate (3.0-3.99) and severe (4.0-5.0) symptoms compatible with gastroparesis. $^{6}$

\section{Data Collection and Statistics}

Information about patients was de-identified and stored on a server as encrypted data. For data analysis, we used IBM SPSS Statistics (Ver. 26, IBM Corporation, USA). Shapiro-Wilks' test was used to assess normality. All results were summarized as median value with interquartile range (IQR). Mann-Whitney $U$-test was used to compare differences between groups. Chi square test was used to compare differences between distributions. Group comparisons were only made between the diabetic and idiopathic subgroups, as other etiological groups were too small to be included in analysis. Spearman's Rank Order Correlation test was used to evaluate associations between continuous variables. To correct for multiple comparisons, we performed the Benjamini-Hochberg procedure. The significance threshold for each comparison was adjusted with a set false discovery rate of $5 \% .^{30}$

\section{Ethical Considerations}

The study was approved by The Western Norway Regional Medical Ethics Committee (2015/58) and was conducted in accordance with the Declaration of Helsinki. All subjects signed informed consent.

\section{Results}

The study population consisted of 107 patients (75 women) who fulfilled the inclusion criteria. Of these, 105 patients were examined with scintigraphy and motility capsule testing. Due to signal loss or other technical errors, output from 96 wireless motility capsule recordings was included for analysis. Eighty-eight patients completed the PAGI-SYM questionnaire. Inclusion flow chart is presented in Figure 2.

\section{All Patients}

Clinical characteristics of all patients are presented in Table 1. Diabetes patients were older $(p=0.001)$, had higher BMI $(p<0.001)$ and used more medications $(p<$ 0.001) than idiopathic patients. When comparing subgroups, idiopathic patients had more nausea, Table 2. Thirty-seven patients (35.2\%) had delayed 4-hour scintigraphy. Of these, 28 had diabetes $(24.8 \%), 7$ (6.4\%) were idiopathic, 1 post-operative $(0.9 \%)$ and 1 of rheumatic $(0.9 \%)$ origin.

In all patients, we found negative correlations between nausea and motility index of the stomach $\left(r_{s}=-0.31, p=\right.$ 0.007), small bowel $\left(r_{s}=-0.41, p<0.001\right)$, and colon $\left(r_{s}=-0.33, p=0.012\right)$, as shown in Figure 3 .

When comparing patients with normal and delayed gastric emptying, we found no differences in symptom severity (Table 2). Neither did we find correlations between symptoms and 4-hour scintigraphy nor any regional transit time measured by the wireless motility capsule.

Table 3 shows gastrointestinal regional and whole gut transit times and comparisons between etiologic subgroups. Significantly more patients in the idiopathic patient group had normal whole gut transit time. We found no other significant differences among diabetic and idiopathic patients.

\section{Idiopathic Etiology}

In the subgroup with idiopathic etiology, 15 (64\%) were female and median (IQR) age was 28 years (24-44). Here, 
A

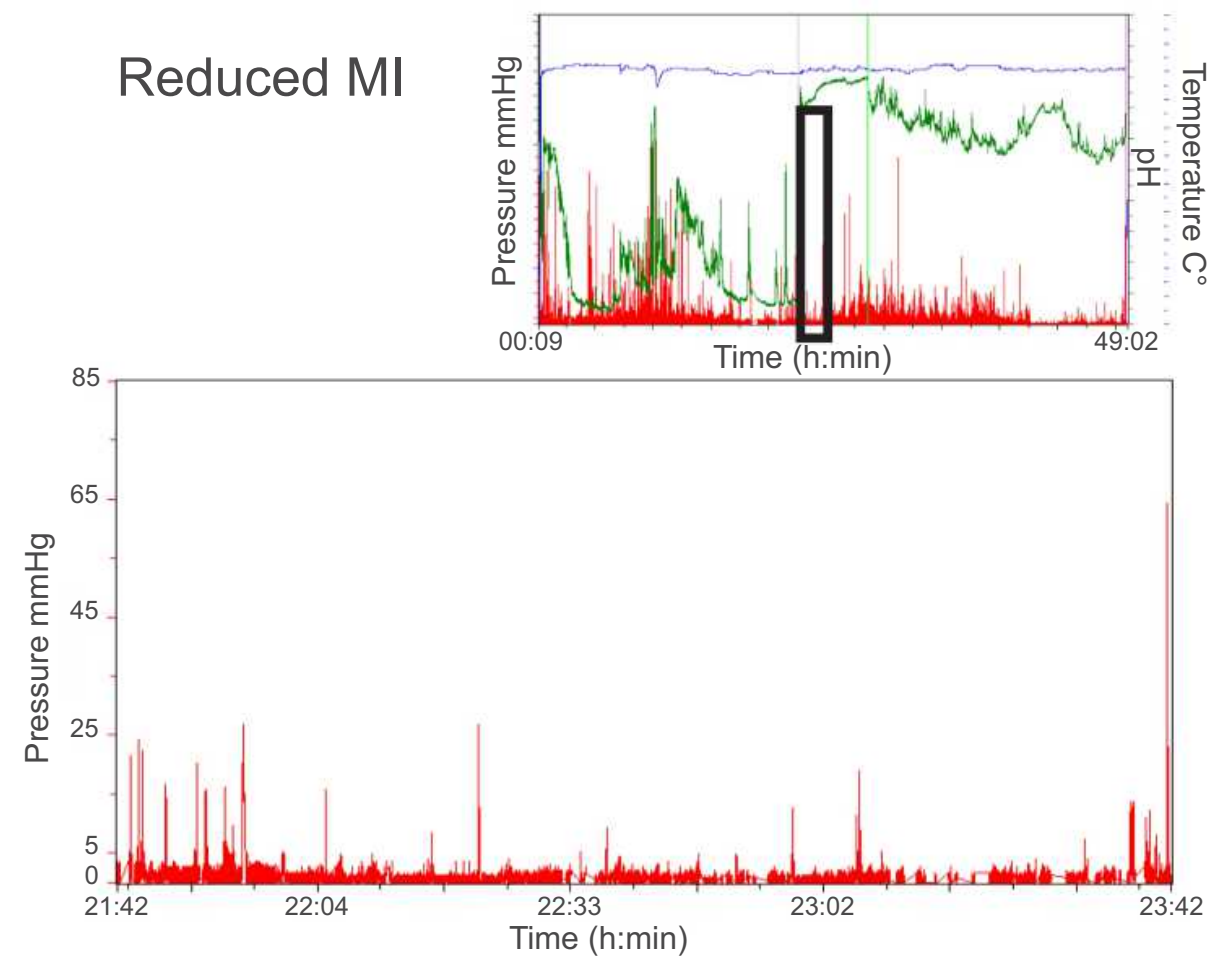

B

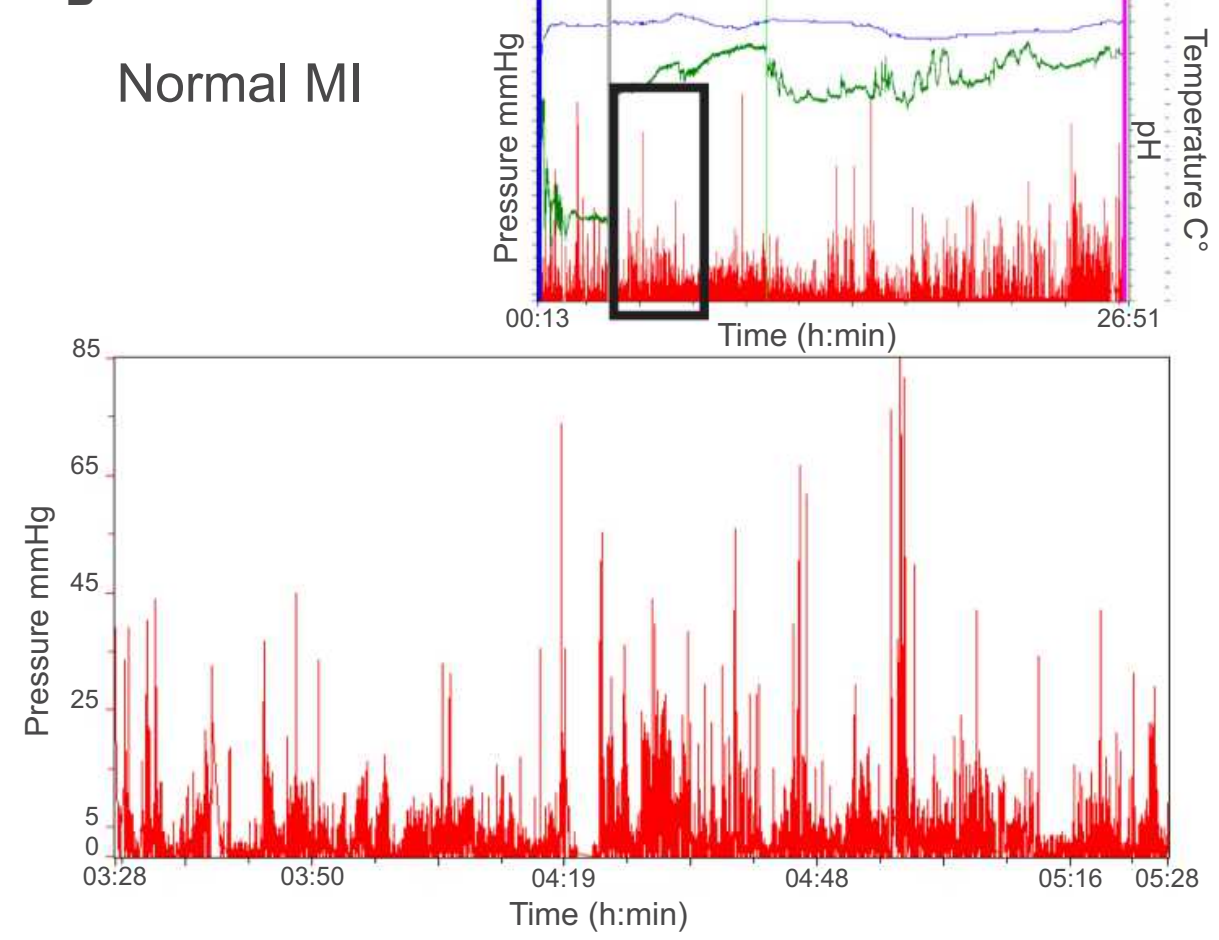

Figure I WMC recordings showing temperature (blue tracing), $\mathrm{pH}$ (green) and pressure recordings (red), time of ingestion (blue vertical line), gastric emptying (grey vertical line), ileocecal junction (green vertical line) and capsule expulsion (pink vertical line). Isolated pressure recordings from the two first hours of the small bowel from each recording are enlarged below. The $\mathrm{Ml}$ is expressed as $\mathrm{mmH}$ *seconds/minute and is calculated as the summed area under the amplitude curve for contractions $>10 \mathrm{mmHg}$, divided by the time window used. Calculation was performed using the MotiliGl ${ }^{\circledR}$ software. (A) WMC results from a patient with impaired small bowel Ml. (B) WMC results from a patient with normal small bowel MI.

Abbreviations: WMC, wireless motility capsule; MI, motility index. 


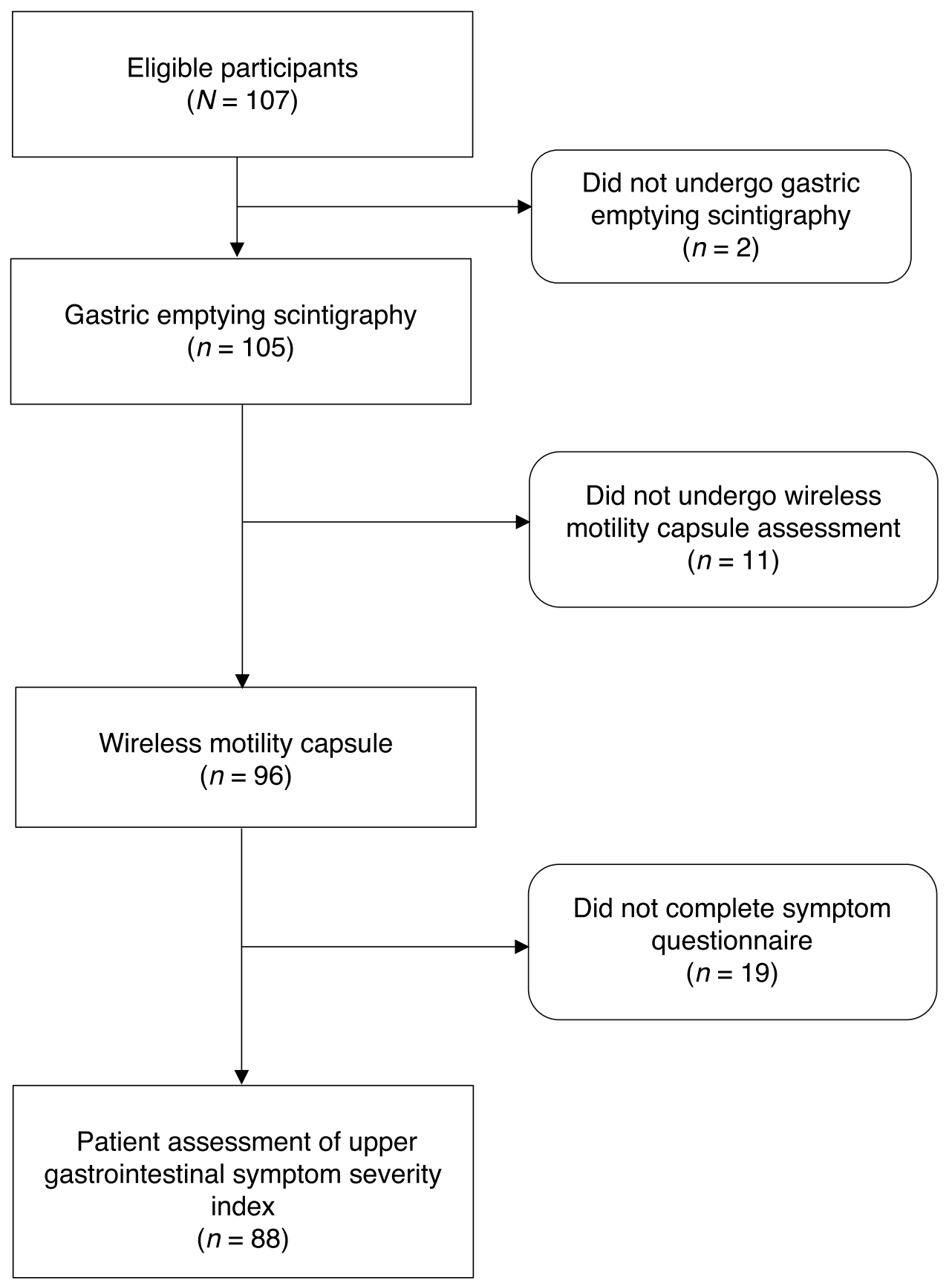

Figure 2 Study flow chart.

symptoms had lasted for a median of 3 years (2-8), BMI was $20.6 \mathrm{~kg} / \mathrm{m}^{2}(19.0-22.4)$ and two patients used opioids. Symptom scores of the idiopathic patient group are shown in Table 2.

In idiopathic patients, we found negative correlations between mean pressure of the stomach $\left(r_{s}=-0.64, p=\right.$ $0.013)$, small bowel motility index $\left(r_{s}=-0.81, p<0.001\right)$ and nausea, as shown in Figure 4. We also found negative correlations between maximum pressure of the small bowel and the subscales of early satiety/postprandial fullness $\left(r_{s}=-0.75, p=0.002\right)$, early satiety $\left(r_{s}=-0.78, p<\right.$ $0.001)$, postprandial fullness $\left(r_{s}=-0.69, p=0.006\right)$, bloating $\left(r_{s}=-0.79, p<0.001\right)$, abdominal distension $\left(r_{s}\right.$ $=-0.67, p=0.007)$ and the GCSI total score $\left(r_{s}=-0.77\right.$, $p<0.001)$, Figure 4. Furthermore, we found a negative correlation between maximum pressure of the colon and early satiety $\left(r_{s}=-0.77, p<0.001\right)$, postprandial fullness $\left(r_{s}=-0.78, p=<0.001\right)$, bloating $\left(r_{s}=-0.67, p=0.009\right)$ 
Table I Clinical Characteristics of Patients with Symptoms Compatible with Gastroparesis

\begin{tabular}{|c|c|}
\hline Variables & Patients \\
\hline $\mathbf{n}$ & 107 \\
\hline \multicolumn{2}{|l|}{ Etiology } \\
\hline Diabetic, n (\%) & $72(67.2)$ \\
\hline Type I diabetes, n (\%) & $59(55.1)$ \\
\hline Type 2 diabetes, $\mathrm{n}(\%)$ & $13(12.1)$ \\
\hline Idiopathic, n (\%) & $23(21.5)$ \\
\hline Post-operative, n (\%) & $4(3.7)$ \\
\hline Rheumatic, n (\%) & $3(2.8)$ \\
\hline Neurologic, n (\%) & $3(2.8)$ \\
\hline Miscellaneous*, n (\%) & $2(1.9)$ \\
\hline Gender (male/female), $\mathrm{n}$ & $32 / 75$ \\
\hline Age, years & $46(31.3-56)$ \\
\hline Symptom duration, years & $4(2.0-9.8)$ \\
\hline BMI, $\mathrm{kg} / \mathrm{m}^{2}$ & $\begin{array}{c}24.1 \\
(20.5-28.7)\end{array}$ \\
\hline Total amount of medications, number & $6(3-10)$ \\
\hline Number of opioid users, $n$ (\%) & $26(24.2)$ \\
\hline Units of alcohol consumed per week & I $(0-1.0)$ \\
\hline $\begin{array}{l}\text { Smoking, n (never smoked/stopped smoking/current } \\
\text { smoker) }\end{array}$ & $4 I / 30 / 34$ \\
\hline \multicolumn{2}{|l|}{ Employment status } \\
\hline On disability benefits, $\mathrm{n}(\%)$ & 7I (67.6) \\
\hline Employed, n (\%) & $18(17.1)$ \\
\hline Student, n (\%) & $6(5.7)$ \\
\hline Retired, n (\%) & $10(9.5)$ \\
\hline Marital status (single/married or cohabitant), $n$ & $37 / 68$ \\
\hline
\end{tabular}

Notes: Data are given as median and interquartile range unless otherwise indicated. Frequencies are given as $\mathrm{n}$ and valid percent. *One colonic Crohn's disease, one cystic fibrosis.

Abbreviation: BMI, body mass index.

and the GCSI total score $\left(r_{s}=74, p=0.002\right)$. There were no significant correlations between any symptom score and 4-h scintigraphy nor any regional transit time.

\section{Diabetic Etiology}

In the subgroup with diabetes, $49(68.1 \%)$ were female and median age was 50 years (IQR 37-56). Symptoms had lasted for a median of 5 years (2-10), BMI was $25.6 \mathrm{~kg} / \mathrm{m}^{2}$ (22.0-29.4) and 19 patients (26\%) used opioids. Symptom scores for the diabetes group are shown in Table 2 .

In diabetes patients, we found a negative correlation between colonic motility index $\left(r_{s}=-0.34, p=0.012\right)$ and the PAGI-SYM total score, as shown in Figure 5. We also found negative correlations between mean pressure of the colon $\left(r_{s}=-0.37, p=0.007\right)$ and upper abdominal pain, and between the mean pressure of the colon $\left(r_{s}=-0.36\right.$, $p=0.008)$ and the composite score of upper abdominal pain. We did not find any correlation between any other symptom score and motility capsule contractility parameters. Neither did we find any association with delayed 4-h scintigraphy nor any regional transit time.

\section{Discussion}

In this prospective study, we investigated patients with gastroparesis symptoms using gastric emptying scintigraphy and wireless motility capsule. Our aim was to explore the association between gastrointestinal motility and symptom severity. In patients with idiopathic etiology, we found moderate to strong negative correlations between gastric and small bowel motility and nausea. We also found strong negative correlations between total GCSI score and maximum pressure of the small bowel and colon. In diabetes patients, we found moderate negative correlations between colonic motility, total PAGISYM score and upper abdominal pain. In the whole patient group, we found moderate negative correlations between gastric, small bowel and colonic motility and nausea. We found no associations between symptom scores and gastric emptying, nor with any other transit time.

The most notable finding of our study was the strong association between upper gastrointestinal symptoms and reduced small bowel motility in patients with suspected idiopathic gastroparesis. Our findings are reminiscent of those made by Barshop et al, when they discovered a moderate correlation between duodenal motility and gastroparesis symptoms. ${ }^{31}$ But in contrast to our study, they only included patients with delayed gastric emptying. Small bowel dysmotility has previously been shown in gastroparesis patients of all etiologies, but the relationship between small bowel motility and symptoms has been conflicting, with few studies involving patients with normal gastric emptying. ${ }^{18,31,32}$ The latter is a weakness of the research field, given the questionable relationship between delayed gastric emptying and patient reported symptoms.

New studies are now emerging, focusing on pathology outside of gastric emptying, as exemplified by a recent study by Cogliandro et al. ${ }^{20}$ They used gastric emptying breath tests and small bowel manometry to demonstrate that $80 \%$ of the patients with gastroparesis symptoms had 


\begin{tabular}{|c|c|c|}
\hline$\frac{\mathscr{g}}{\frac{2}{\pi}}$ & 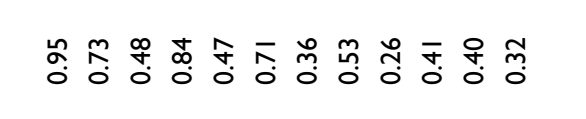 & 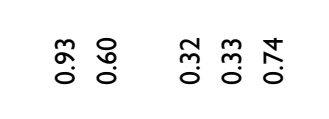 \\
\hline $\begin{array}{l}\widehat{Q} \\
0 \\
\text { II } \\
\Xi \\
\vdots \\
\mathbf{z}\end{array}$ & 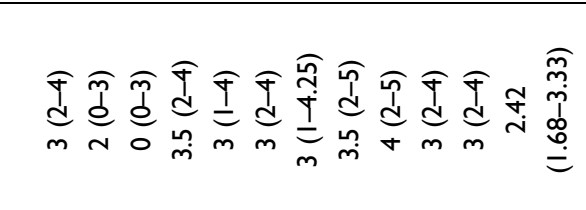 & 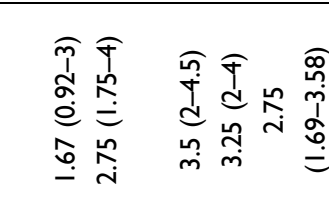 \\
\hline 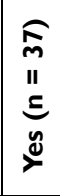 & 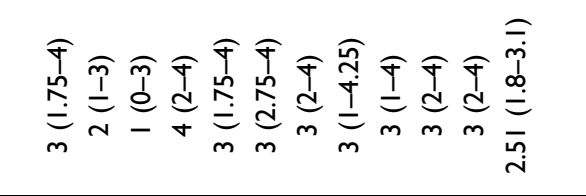 & 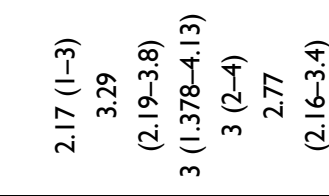 \\
\hline 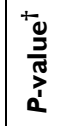 & 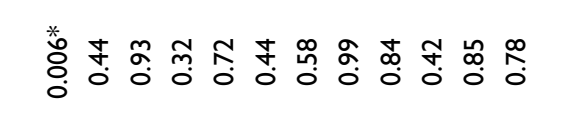 & g. \\
\hline 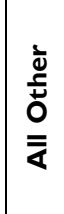 & 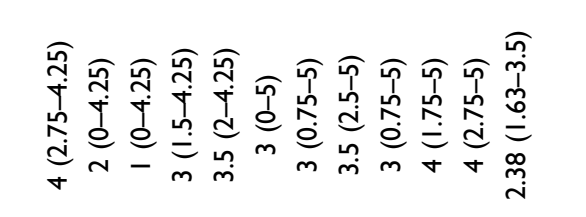 & 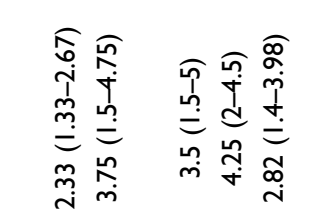 \\
\hline 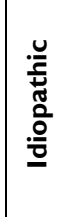 & 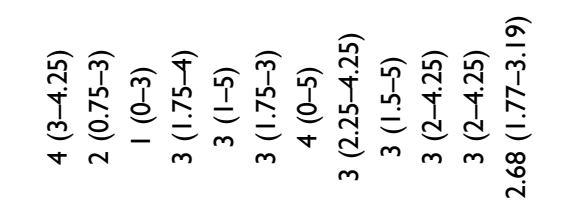 & 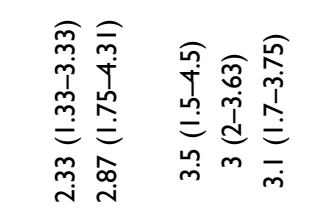 \\
\hline 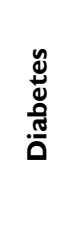 & 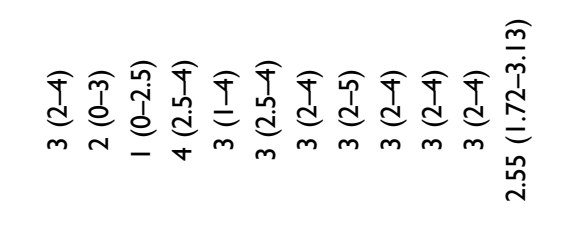 & 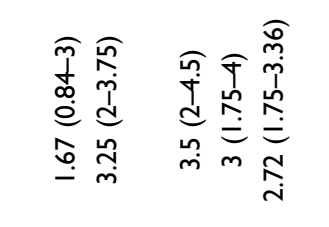 \\
\hline 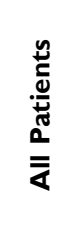 & 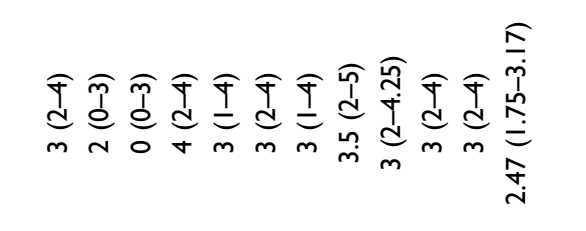 & 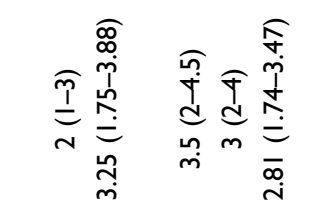 \\
\hline & 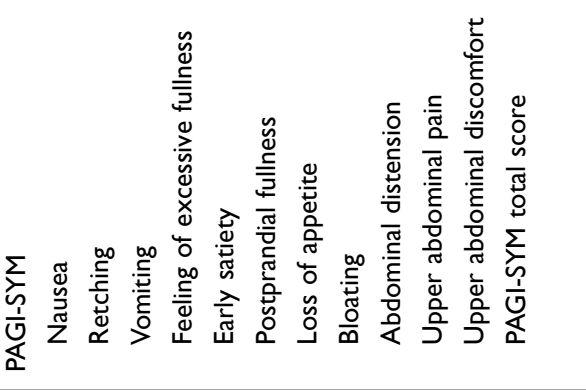 & 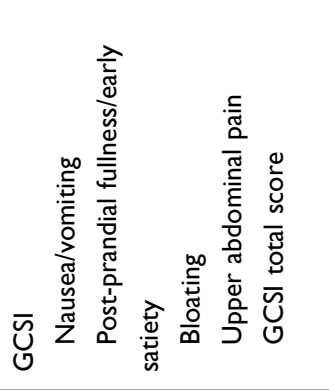 \\
\hline
\end{tabular}



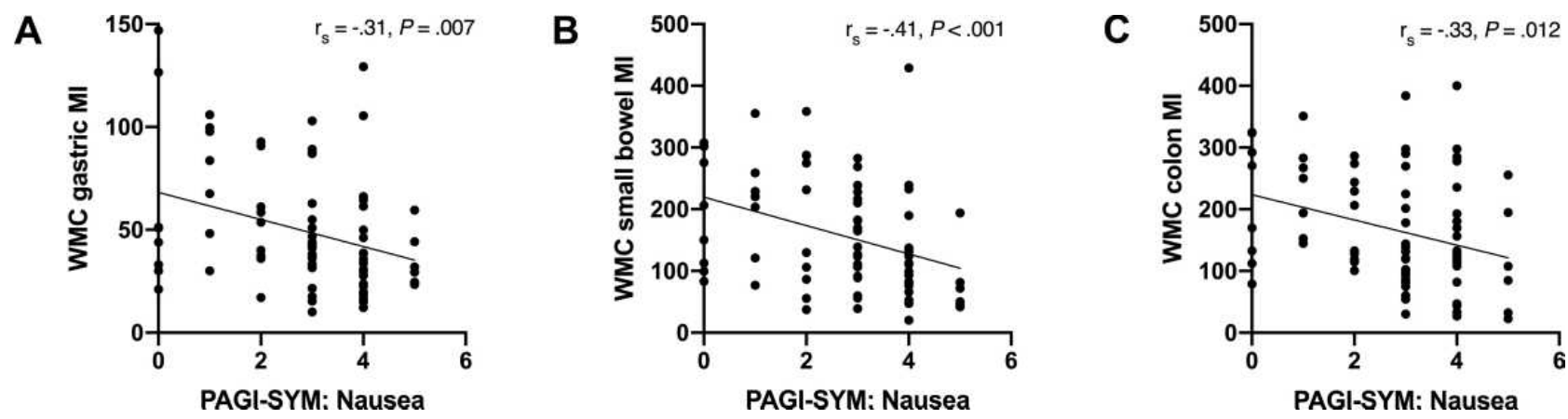

Figure 3 Correlations between symptom severity and gastrointestinal motility in the whole patient group. Spearman's rank-order correlation and linear regression analyses were used to examine associations among the variables. (A) Correlation between MI of the stomach and nausea as measured with PAGI-SYM, (B) Correlation between MI of the small bowel and nausea as measured with PAGI-SYM. (C) Correlation between MI of the colon and nausea as measured with PAGI-SYM.

Abbreviations: MI, motility index; PAGI-SYM, Patient Assessment of Gastrointestinal Symptom Severity Index.

enteric dysmotility, while only $24 \%$ had delayed gastric emptying. They also found that patients with enteric dysmotility often had more severe disease. However, contrasting our findings, they found no difference in symptoms comparing patients with and without enteric dysmotility.

When looking at all patients together, we identified an association between reduced colonic motility index and nausea. Similar findings were made by Kolar et al. ${ }^{33}$ They found that a large proportion of patients with chronic nausea and vomiting, had findings consistent with colonic transit or rectal evacuation disorders. Hasler et al, on the other hand, found no difference in most gastroparesis symptoms when comparing patients with high and low number of colonic contractions. ${ }^{16}$ However, they did find an association between reduced colonic motility and upper abdominal pain, the same as we did in our diabetes group. Our findings in idiopathic patients also support an association between upper gastrointestinal symptoms and colonic hypomotility.

Comparing symptoms in patients with normal and delayed gastric emptying, we found no difference with neither scintigraphy nor wireless motility capsule. These

Table 3 Intestinal Transit Times

\begin{tabular}{|c|c|c|c|c|}
\hline \multirow[t]{2}{*}{ Transit Times } & \multicolumn{3}{|c|}{ Etiology } & \multirow[t]{2}{*}{ P-value* } \\
\hline & All Patients & Diabetes & Idiopathic & \\
\hline Gastric emptying time & 353 minutes $(252-1432)$ & 340 minutes $(208-1490)$ & 344 minutes $(260-1198)$ & 0.958 \\
\hline Rapid (<105 minutes) & 0 & 0 & 0 & - \\
\hline Normal & 42 & 32 & 7 & 0.399 \\
\hline Delayed (>300 minutes) & 54 & 35 & 12 & 0.399 \\
\hline Small bowel transit time & 300 minutes $(220-40 I)$ & 280 minutes $(213-368)$ & 356 minutes $(287-469)$ & 0.018 \\
\hline Rapid (<135 minutes) & 4 & 3 & I & 0.869 \\
\hline Normal & 87 & 50 & 17 & 0.757 \\
\hline Delayed (>480 minutes) & 2 & 2 & 0 & 0.451 \\
\hline Colonic transit time & 2618 minutes (I $124-4487)$ & 2618 minutes $(1163-4300)$ & 2856 minutes $(1046-4277)$ & 0.903 \\
\hline Rapid (<300 minutes) & 6 & 5 & 0 & 0.221 \\
\hline Normal & 49 & 33 & 10 & 0.764 \\
\hline Delayed (>3030 minutes) & 38 & 26 & 8 & $0.77 \mid$ \\
\hline Whole gut transit time & 4166 minutes (2079-6269) & $37 / 4$ minutes (2079-6073) & 3576 minutes $(1613-5342)$ & 0.770 \\
\hline Rapid (<645 minutes) & 0 & 0 & 0 & - \\
\hline Normal & 47 & 34 & 10 & 0.050 \\
\hline Delayed (>4I25 minutes) & 49 & 33 & 9 & 0.932 \\
\hline
\end{tabular}

Notes: Intestinal transit times reported as median and interquartile range. Number of patients divided into groups of rapid, normal and delayed transit times in each intestinal segment according to cut-offs as proposed by Wang et al. ${ }^{25} *$ Comparison of idiopathic and diabetic patients assessed by Mann-Whitney $U$-test and Chi square test. 

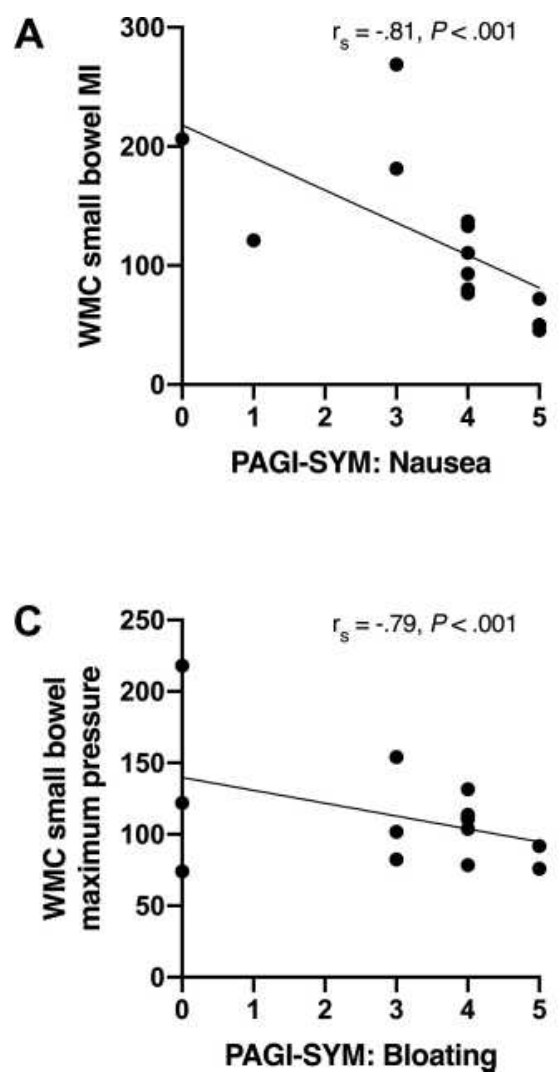

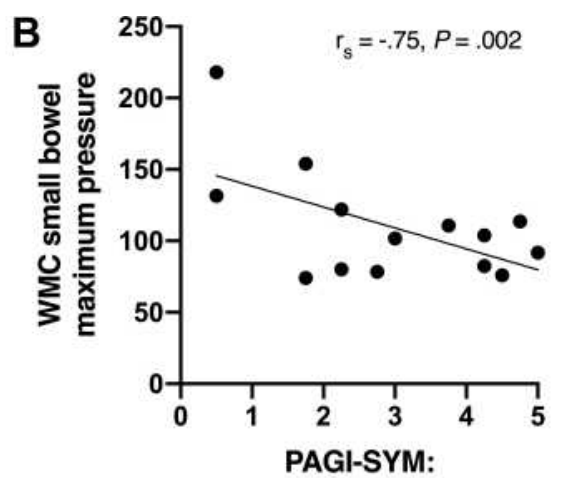

Early satiety/postprandial fullness

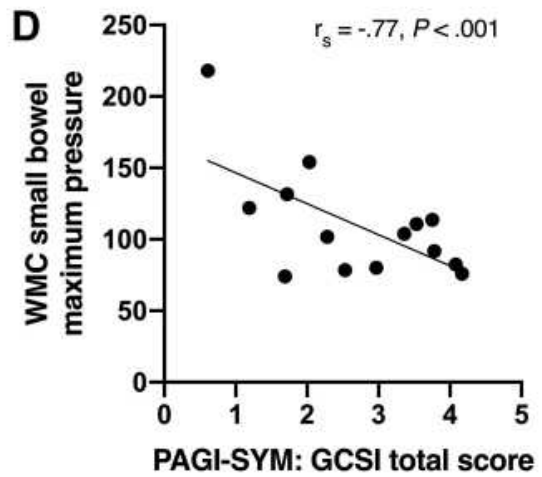

Figure 4 Correlations between symptom severity and small bowel motility in patients with idiopathic etiology. Spearman's rank-order correlation and linear regression analyses were used to examine associations among the variables. (A) Correlation between MI of the small bowel and nausea as measured with PAGI-SYM. (B) Correlation between maximum pressure of the small bowel and early satiety/postprandial fullness. (C) Correlation between maximum pressure of the small bowel and bloating. (D) Correlation between maximum pressure of the small bowel and GCSI total score.

Abbreviations: MI, motility index; PAGI-SYM, Patient Assessment of Gastrointestinal Symptom Severity Index; GCSI, Gastroparesis Cardinal Symptom Index.

results are in accordance with previous studies. ${ }^{16,34}$ The patients in our normal gastric emptying group likely fulfill criteria for both functional dyspepsia and gastroparesislike syndrome. In a recent study, functional dyspepsia and gastroparesis was shown to be interchangeable syndromes. ${ }^{35}$ Approximately $40 \%$ of the 944 patients in the study were reclassified as functional dyspepsia or gastroparesis on a 48-week follow-up and this was not associated with changes in symptom severity. Both groups also showed similar histopathology on full-thickness biopsies. Further, gastroparesis-like and gastroparesis also display similar symptom severity, histopathological changes, and myoelectrical activity $^{3-5,36}$ In this study, we also found a strong negative correlation between nausea and mean pressure of the stomach in idiopathic patients, contrasting other comparable wireless motility capsule studies. ${ }^{16,31}$ A reasonable interpretation may be that patients with gastroparesis, the so-called gastroparesislike syndrome and functional dyspepsia are all part of a spectrum, where patients with delayed gastric emptying have more serious neuromuscular or mesenchymal dysfunction. ${ }^{35}$ Both our normal and delayed gastric emptying group therefore likely have such a gastric neuromuscular dysfunction, with or without other intestinal motor dysfunction.

Whether the extragastric motor dysfunctions found in this study represent pathology of separate gastrointestinal disorders or are part of the same spectrum cannot be conclusively answered by this study. However, small bowel dysmotility is also seen in both patients with gastroparesis, functional dyspepsia and irritable bowel syndrome. ${ }^{37,38}$ As discussed previously, impaired colon motility are also found in constipated patients. In one study using Rome IV criteria, $64 \%$ of the patients with functional dyspepsia or irritable bowel syndrome was shown to fulfill criteria for both disorders. ${ }^{39}$ It is therefore likely that part of our patient group also fulfills criteria for irritable bowel syndrome. Further studies systematically using Rome IV criteria, pan-enteric motility measures and supplemental pathological markers such as full- 


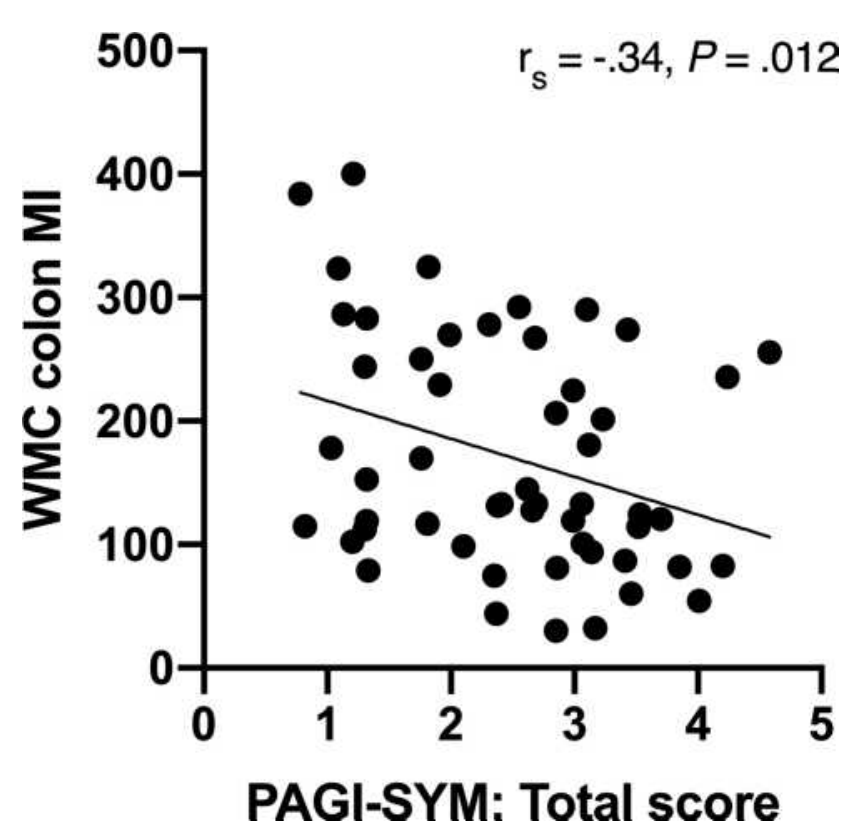

Figure 5 Correlations between symptom severity and colonic motility in patients with diabetic etiology. Spearman's rank-order correlation and linear regression analyses were used to examine associations among the variables. Correlation between $\mathrm{MI}$ of the colon and PAGI-SYM: Total score.

Abbreviations: MI, motility index; PAGI-SYM, Patient Assessment of Gastrointestinal Symptom Severity Index.

thickness biopsies are needed to resolve whether segmental dysmotility can be attributed to separate disorders in patients with similar clinical features.

Interpreting the results, we find it likely that intestinal hypomotility plays a more prominent role in the generation of gastroparesis symptoms than previously believed. As symptoms alone cannot be used to differentiate between dysmotility in different gastrointestinal regions, patients may benefit from a more comprehensive assessment of intestinal motility regardless of gastric emptying rates. ${ }^{40}$ Thus, performing gastric emptying scintigraphy alone may miss pathology in a significant number of patients. Here, the wireless motility capsule might prove to be a good alternative, measuring gastric emptying, intestinal transit times and other motility parameters in one test. In contrast to antroduodenal manometry, the method is very well tolerated by patients. Furthermore, the procedure can be performed in the outpatient clinic and is easy to interpret, with excellent inter-rater reliability. ${ }^{41}$

Our study had some limitations. The composition of the meal served before motility testing deviated somewhat from the standard protocol. While the SmartBar ${ }^{\mathbb{R}}$ is almost identical in caloric and macronutritional content to the standard eggwhite meal recommended for gastric emptying scintigraphy, the addition of a boiled egg elevated the total caloric content by $90 \mathrm{kcal}$ as well as containing additional fat and protein. On the other hand, simultaneous investigation with scintigraphy and wireless motility capsule was a major strength of the study, minimizing intra-individual day-to-day variations in gastric emptying. To avoid spurious associations, we chose to correct for multiple comparisons with the BenjaminiHochberg procedure, a method reducing the risk of type I errors, without being so conservative that it facilitates type II errors. Another strength of the study was its prospective, single-center inclusion, allowing for isolation of the factors we wished to test for, as opposed to most studies performed with the wireless motility capsule, having a retrospective design.

\section{Conclusions}

In this study, we found substantial associations between gastroparesis symptoms and intestinal hypomotility measured by the wireless motility capsule. Associations were particularly strong in the idiopathic subgroup. In contrast, we found no association between gastric emptying and symptoms. Based on our results, pan-enteric investigation of motility is recommended in both diabetes and idiopathic patients with symptoms suggestive of gastroparesis.

\section{Acknowledgment}

An abstract from the study was presented at the NeuroGASTRO congress in Lisbon, Portugal, September 5-7, 2019. ${ }^{42}$

\section{Author Contributions}

All authors made a significant contribution to the work reported, whether that is in the conception, study design, execution, acquisition of data, analysis and interpretation, or in all these areas; took part in drafting, revising or critically reviewing the article; gave final approval of the version to be published; have agreed on the journal to which the article has been submitted; and agree to be accountable for all aspects of the work.

\section{Funding}

The study has been funded by Haukeland University Hospital. Writing of the manuscript was in part funded by the Norwegian research council by a grant given through the medical student research programme at the University of Oslo. The sponsors had no role in any part of the research process. 


\section{Disclosure}

Mattis Bekkelund reports grants from Norwegian Research Council and that the Haukeland University Hospital sponsors had no role in any part of the research process, during the conduct of the study. Elisabeth K. Steinsvik reports grants from Helse Vest during the conduct of the study. The authors reported no other potential conflicts of interest for this work.

\section{References}

1. Camilleri M, Parkman HP, Shafi MA, Abell TL, Gerson L. Clinical guideline: management of gastroparesis. Am $J$ Gastroenterol. 2013;108(1):18-37;quiz 38. doi:10.1038/ajg.2012.373

2. Nguyen LA, Snape WJ. Clinical presentation and pathophysiology of gastroparesis. Gastroenterol Clin North Am. 2015;44(1):21-30. doi:10.1016/j.gtc.2014.11.003

3. Pasricha PJ, Colvin R, Yates K, et al. Characteristics of patients with chronic unexplained nausea and vomiting and normal gastric emptying. Clin Gastroenterol Hepatol. 2011;9(7):567. doi:10.1016/j. cgh.2011.03.003

4. Anaparthy R, Pehlivanov N, Grady J, Yimei H, Pasricha PJ. Gastroparesis and gastroparesis-like syndrome: response to therapy and its predictors. Dig Dis Sci. 2009;54(5):1003-1010. doi:10.1007/ s10620-009-0717-4

5. Bashashati M, Moraveji S, Torabi A, et al. Pathological findings of the antral and pyloric smooth muscle in patients with gastroparesis-like syndrome compared to gastroparesis: similarities and differences. Dig Dis Sci. 2017;62(10):2828-2833. doi:10.1007/ s10620-017-4629-4

6. Parkman HP, Yates K, Hasler WL, et al. Clinical features of idiopathic gastroparesis vary with sex, body mass, symptom onset, delay in gastric emptying, and gastroparesis severity. Gastroenterology. 2011;140(1):101-115. doi:10.1053/j.gastro.2010.10.015

7. Talley NJ, Ford AC, Longo DL. Functional Dyspepsia. $N$ Engl J Med. 2015;373(19):1853-1863. doi:10.1056/NEJMra1501505

8. Tack J, Drossman DA. What's new in Rome IV? Neurogastroenterol Motil. 2017;29(9).

9. Camilleri M, Grover M, Farrugia G. What are the important subsets of gastroparesis? Neurogastroenterol Motil. 2012;24(7):597-603. doi:10.1111/j.1365-2982.2012.01942.x

10. Sangnes DA, Softeland E, Teigland T, Dimcevski G. Comparing radiopaque markers and (13)C-labelled breath test in diabetic gastroparesis diagnostics. Clin Exp Gastroenterol. 2019;12:193-201. doi:10.2147/CEG.S200875

11. Bekkelund M, Sangnes DA, Gunnar Hatlebakk J, Aabakken L. Pathophysiology of idiopathic gastroparesis and implications for therapy. Scand J Gastroenterol. 2019;54(1):8-17. doi:10.1080/ 00365521.2018.1558280

12. Vijayvargiya P, Jameie-Oskooei S, Camilleri M, Chedid V, Erwin PJ, Murad MH. Association between delayed gastric emptying and upper gastrointestinal symptoms: a systematic review and meta-analysis. Gut. 2018;68:804-813. doi:10.1136/gutjnl-2018-316405

13. Parkman HP, Wilson LA, Hasler WL, et al. Abdominal pain in patients with gastroparesis: associations with gastroparesis symptoms, etiology of gastroparesis, gastric emptying, somatization, and quality of life. Dig Dis Sci. 2019;64(8):2242-2255. doi:10.1007/ s10620-019-05522-9

14. Vijayvargiya P, Camilleri M, Chedid V, Mandawat A, Erwin PJ, Murad MH. Effects of promotility agents on gastric emptying and symptoms: a systematic review and meta-analysis. Gastroenterology. 2019;156(6):1650-1660.
15. Sangnes DA, Softeland E, Bekkelund M, et al. Wireless motility capsule compared with scintigraphy in the assessment of diabetic gastroparesis. Neurogastroenterol Motil. 2020;32(4):e13771

16. Hasler WL, May KP, Wilson LA, et al. Relating gastric scintigraphy and symptoms to motility capsule transit and pressure findings in suspected gastroparesis. Neurogastroenterol Motil. 2018;30(2): e13196. doi:10.1111/nmo.13196

17. Surjanhata B, Brun R, Wilding G, Semler J, Kuo B. Small bowel fed response as measured by wireless motility capsule: comparative analysis in healthy, gastroparetic, and constipated subjects. Neurogastroenterol Motil. 2018;30(5):e13268. doi:10.1111/ nmo. 13268

18. Lee A, Wilding G, Kuo B. Variable abnormal physiological motility in the proximal upper gastrointestinal tract in gastroparesis. Neurogastroenterol Motil. 2012;24(7):652-657, e276. doi:10.1111/ j.1365-2982.2012.01905.x

19. Kloetzer L, Chey WD, McCallum RW, et al. Motility of the antroduodenum in healthy and gastroparetics characterized by wireless motility capsule. Neurogastroenterol Motil. 2010;22(5):527-533, e117. doi:10.1111/j.1365-2982.2010.01468.x

20. Cogliandro RF, Rizzoli G, Bellacosa L, et al. Is gastroparesis a gastric disease? Neurogastroenterol Motil. 2019;31(5):e13562. doi:10.1111/ nmo. 13562

21. Malagelada C, Malagelada JR. Small bowel motility. Curr Gastroenterol Rep. 2017;19(6):26. doi:10.1007/s11894-017-0565-x

22. Abell TL, Camilleri M, Donohoe K, et al. Consensus recommendations for gastric emptying scintigraphy: a joint report of the American Neurogastroenterology and Motility Society and the Society of Nuclear Medicine. J Nucl Med Technol. 2008;36(1):44-54. doi:10.2967/jnmt.107.048116

23. Zarate N, Mohammed SD, O'Shaughnessy E, et al. Accurate localization of a fall in $\mathrm{pH}$ within the ileocecal region: validation using a dual-scintigraphic technique. Am $J$ Physiol Gastrointest Liver Physiol. 2010;299(6):G1276-1286. doi:10.1152/ajpgi.00127.2010

24. Farmer AD, Wegeberg AL, Brock B, et al. Regional gastrointestinal contractility parameters using the wireless motility capsule: inter-observer reproducibility and influence of age, gender and study country. Aliment Pharmacol Ther. 2018;47(3):391-400. doi:10.1111/apt.14438

25. Wang YT, Mohammed SD, Farmer AD, et al. Regional gastrointestinal transit and $\mathrm{pH}$ studied in 215 healthy volunteers using the wireless motility capsule: influence of age, gender, study country and testing protocol. Aliment Pharmacol Ther. 2015;42(6):761-772. doi:10.1111/apt.13329

26. Ouyang A, Sunshine AG, Reynolds JC. Caloric content of a meal affects duration but not contractile pattern of duodenal motility in man. Dig Dis Sci. 1989;34(4):528-536. doi:10.1007/BF01536328

27. Teigland T, Iversen MM, Sangnes DA, Dimcevski G, Softeland E. A longitudinal study on patients with diabetes and symptoms of gastroparesis - associations with impaired quality of life and increased depressive and anxiety symptoms. J Diabetes Complications. 2018;32(1):89-94. doi:10.1016/j.jdiacomp.2017. 10.010

28. Rentz AM, Kahrilas P, Stanghellini V, et al. Development and psychometric evaluation of the patient assessment of upper gastrointestinal symptom severity index (PAGI-SYM) in patients with upper gastrointestinal disorders. Qual Life Res. 2004;13(10):1737-1749. doi:10.1007/s11136-004-9567-x

29. Revicki DA, Rentz AM, Dubois D, et al. Development and validation of a patient-assessed gastroparesis symptom severity measure: the Gastroparesis Cardinal Symptom Index. Aliment Pharmacol Ther. 2003;18(1):141-150. doi:10.1046/j.1365-2036.2003.01612.x

30. Feser WJ, Fingerlin TE, Strand MJ, Glueck DH. Calculating average power for the Benjamini-Hochberg procedure. $J$ Stat Theory Appl. 2009;8(3):325-352. 
31. Barshop K, Staller K, Semler J, Kuo B. Duodenal rather than antral motility contractile parameters correlate with symptom severity in gastroparesis patients. Neurogastroenterol Motil. 2015;27 (3):339-346. doi:10.1111/nmo.12496

32. Kuo B, Maneerattanaporn M, Lee AA, et al. Generalized transit delay on wireless motility capsule testing in patients with clinical suspicion of gastroparesis, small intestinal dysmotility, or slow transit constipation. Dig Dis Sci. 2011;56(10):2928-2938. doi:10.1007/ s10620-011-1751-6

33. Kolar GJ, Camilleri M, Burton D, Nadeau A, Zinsmeister AR. Prevalence of colonic motor or evacuation disorders in patients presenting with chronic nausea and vomiting evaluated by a single gastroenterologist in a tertiary referral practice. Neurogastroenterol Motil. 2014;26(1):131-138. doi:10.1111/nmo.12242

34. Hasler W, May K, Pasricha P, et al. Relation of gastroparesis symptom severity to gastric, small bowel and colon transit and contraction profiles on wireless motility capsule testing in a large multicenter cohort (abstract). Gastroenterology. 2016;150(4):S725. doi:10.1016/ S0016-5085(16)32470-2

35. Pasricha PJ, Grover M, Yates KP, et al. Functional dyspepsia and gastroparesis in tertiary care are interchangeable syndromes with common clinical and pathological features. Gastroenterology. 2021. doi:10.1053/j.gastro.2021.01.230

36. Angeli TR, Cheng LK, Du P, et al. Loss of interstitial cells of cajal and patterns of gastric dysrhythmia in patients with chronic unexplained nausea and vomiting. Gastroenterology. 2015;149(1):56-66 e55. doi:10.1053/j.gastro.2015.04.003
37. Wilmer A, Van Cutsem E, Andrioli A, Tack J, Coremans G, Janssens J. Ambulatory gastrojejunal manometry in severe motility-like dyspepsia: lack of correlation between dysmotility, symptoms, and gastric emptying. Gut. 1998;42(2):235-242. doi:10.1136/gut.42.2.235

38. Evans PR, Bak YT, Shuter B, Hoschl R, Kellow JE. Gastroparesis and small bowel dysmotility in irritable bowel syndrome. Dig Dis Sci. 1997;42(10):2087-2093. doi:10.1023/A:1018874602790

39. von Wulffen M, Talley NJ, Hammer J, et al. Overlap of irritable bowel syndrome and functional dyspepsia in the clinical setting: prevalence and risk factors. Dig Dis Sci. 2019;64(2):480-486. doi:10.1007/s10620-018-5343-6

40. Arora Z, Parungao JM, Lopez R, Heinlein C, Santisi J, Birgisson S. Clinical utility of wireless motility capsule in patients with suspected multiregional gastrointestinal dysmotility. Dig Dis Sci. 2015;60 (5):1350-1357. doi:10.1007/s10620-014-3431-9

41. Sangnes DA, Softeland E, Bekkelund M, et al. Wireless motility capsule compared with scintigraphy in the assessment of diabetic gastroparesis. Neurogastroenterol Motil. 2019;32:e13771. doi:10.1111/nmo.13771

42. Bekkelund M, Sangnes DA, Aabakken L, Dimcevski G, Hatlebakk JG. Non-diabetic patients with gastroparesis-like symptoms assessed with gastric emptying scintigraphy and wireless motility capsule. Neurogastroenterol Motil. 2019;31(S4):77.
Clinical and Experimental Gastroenterology

\section{Publish your work in this journal}

Clinical and Experimental Gastroenterology is an international, peerreviewed, open access, online journal publishing original research, reports, editorials, reviews and commentaries on all aspects of gastroenterology in the clinic and laboratory. This journal is indexed on American Chemical Society's Chemical Abstracts Service (CAS).

\section{Dovepress}

The manuscript management system is completely online and includes a very quick and fair peer-review system, which is all easy to use. Visit http://www.dovepress.com/testimonials.php to read real quotes from published authors. 